\title{
Identification of Probable Iron Ore using Ground Magnetic Exploration Technique
}

\author{
K.S. Siva Subramanian, Abhishek Kumar Tripathi, Ramesh Kant
}

\begin{abstract}
Geophysics is one of the branches of natural science which is concerned with the physical process and physical properties of the earth. Exploration physics is the sub branch of the geophysics which is very important for any mining related activities. The exploration activities help the mining industries to locate the probable mineral or ore reserve. There is various physical method of exploration process such as, seismic, gravitational, electrical, magnetic and electromagnetic to locate the position and volume of mineral by direct or indirect approach. In this paper, an identification study was performed using ground magnetic technique to identify the probable iron ore in the site under the study. In the current ground magnetic study, it was observed that the, it is a confident suggestion that iron ore is available in this area. As per the conducted field analysis, the ore bodies available in this area are floats, deposited and in order to rule out this concept Vertical Electrical Sounding (VES) technique was recommended.
\end{abstract}

Keywords: Geophysics, exploration, ground magnetic survey, vertical electrical sounding.

\section{INTRODUCTION}

The mineral exploration is one of the vital activities in the mining industry which helps to uncover the mineral potential so that a country can utilize its full mineral paternal. The mineral exploration is the technique of finding the mineral or ore deposit in a commercially viable manner. It helps in minimizing the risk of mining business by generating adequate information of the surface which is going to be mined. Mineral exploration having four essential stages namely, area selection, target generation, resource evaluation ad reserve estimation [1]. The adequate information of reserve evaluation and estimation could play an important role for the mineral based industries. In this context, the finding of reserve becomes very much essential which can be carried out by using the concept of exploration geophysics [2].

Exploration geophysics is one of the branches of geophysics which is used to identify the type and volume of

Revised Manuscript Received on April 25, 2020.

* Correspondence Author

Abhishek Kumar Tripathi*, Mining Engineering, Aditya Engineering College, Surampaelm, Kakinda, Andhra Pradesh, India. Email: abhishekkumar@aec.edu.in

K.S. Siva Subramanian, Mining Engineering, AMET University, Chennai, India. Email: hod_mining@ametuniv.ac.in

Ramesh Kant, Mining Engineering, AMET University, Chennai, India. Email: rameshkant2010@gmail.com

(c) The Authors. Published by Blue Eyes Intelligence Engineering and Sciences Publication (BEIESP). This is an open access article under the CC BY-NC-ND license (http://creativecommons.org/licenses/by-nc-nd/4.0/) mineral present under the earth surface. The exploration geophysics uses the physical method namely, seismic, gravitational, electrical, magnetic and electromagnetic to locate the position and volume of mineral by direct or indirect approach [3]. In magnetic technique the aeromagnetic survey is being used to map the magnetic anomalies of the under-earth surface. An aeromagnetic survey usage the magnetometer behind an aircraft and follow the same principle of magnetic survey with the allowing the larger surface area [4]. The magnetometer of aircraft files measures and records the complete power of the magnetic field at the sensor and gathered the required information about the surface [5]. The best geophysical procedure for identification of Iron ore body is ground magnetic survey. As the haematite and Magnetite have ferro-magnetic properties so the finding of probable iron ore reserves becomes easy by adopting the ground magnetic survey. The usages of ground magnetic survey aids in understanding the behaviour and complexity of sub surface thin layer [6]. The main objective of ground magnetic studies is to understand the sub-surface implications of iron ore bodies mainly Banded Iron Formation (BIF), Banded Magnetite Quartzite (BMQ) etc deposits. This ground magnetic survey obeys the non-invasive nature of geophysical technique where it gathered the require information without affecting the surface condition. It is a low impact survey technique which is usage a measuring instrument called magnetometer [7].

The magnetometer instrument is lighter in weight and it can be transported by simply backpack mechanism. The measurement can be taken at one point or in a grid profile without disturbing the surface. The magnetometers are basically three types namely, fluxgate, proton-precession and Alkali-vapor magnetometer [8].

In the present research work the field study for identification of probable iron ore reserves was carried out using ground magnetic technique. Thus, in order to conduct the survey of probable iron ore reserve in the field the proton precession magnetometer was used and the study was performed for the south east central zone of India. This paper consists of five different section where section I represent the introduction of the present work. Section II shows the about the considered site (regional geology of the area) which is followed by the section III i.e., methodology adopted for the present research work. Section IV represents the results and discussion of this paper which is followed by the conclusions in the section $\mathrm{V}$.

\section{Published By:}

Blue Eyes Intelligence Engineering

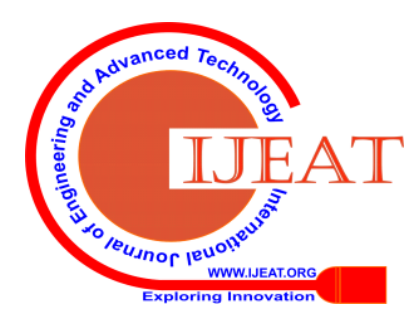




\section{Identification of Probable Iron Ore using Ground Magnetic Exploration Technique}

\section{ABOUT THE SITE}

The ground magnetic survey was carried out on the eastern periphery of north Odisha which is situated at $21^{\circ} 55^{\prime} 00^{\prime \prime} \mathrm{N}$ and $85^{\circ} 25^{\prime} 00^{\prime \prime} \mathrm{E}$ and $21^{\circ} 59^{\prime} 00^{\prime \prime} \mathrm{N}$ and $85^{\circ} 27^{\prime} 00^{\prime \prime} \mathrm{E}$. The site having the key horizon of Banded Iron Formation (BIF) and iron ores which is more appropriate for the ground magnetic survey technique. The geological map of the considered site is shown in Figure 1. There are some exposures of basement rock belonging to OMG in the eastern and western part of the fault bounded basin, which include amphibolite's, tremolite-actinolite schist and granite (Singh hum granite). The basin deposits are structured into series of anticlines and synclines by iron ore orogeny that run parallel in NE-SW in Badampahar and Sulaipat sector but loses symmetry in Gorumahisani sector. In the area under the study Some iron formations (Magnetite dyke) of later appearance owe to the igneous origin and maintain intrusive character with the rocks particularly in the Sulaipat sector.

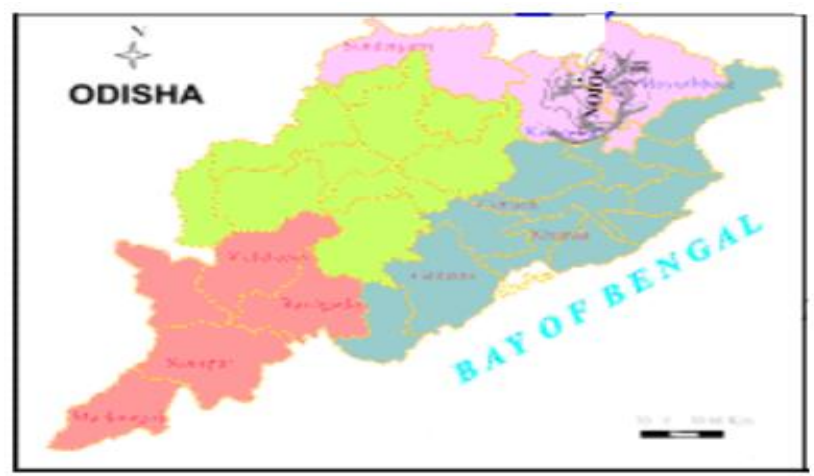

Fig.1. Geological map of the considered site

\section{GROUND MAGNETIC SURVEY- FIELD OBSERVATIO}

The best geophysical procedure for identification of Iron ore body is ground magnetic survey as haematite and Magnetite have ferro-magnetic properties. The main objective of ground magnetic studies is to understand the sub-surface implications of iron ore bodies mainly BIF, BMQ etc deposits. Ground magnetic surveys are planned with $50 \mathrm{~m}$ traverse interval using the high accurate magnetometers which can measure local the magnetic fields with a high degree of precision. In this study, Gem Systems GSM-19 WALKMAG magnetometers are used which is shown in Figure 2. Further, the planned ground magnetic lines at an interval of $50 \mathrm{~m}$ for this study is presented in Figure 3.

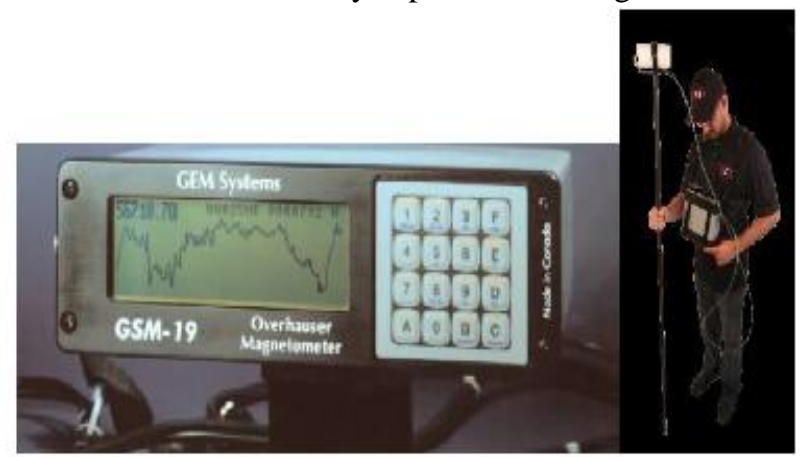

Fig.2. Magnetometer console and men in-action

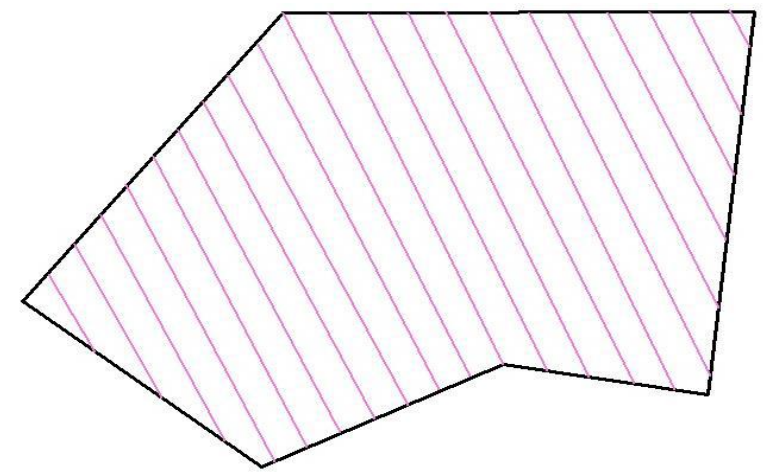

Fig.3. Ground Magnetic lines planned at $50 \mathrm{~m}$ traverse interval

Base and rover data are the basic outputs from the location from where the instrument data is acquired. A base station magnetometer is used to record TMI value at a constant location with respect to time (readings are taken at regular time intervals) are used as base reference during the entire period of survey.

This data is used to make necessary corrections (diurnal corrections) in the field magnetometer (Rover or Walking Magnetometer) data for varied locations as well as to obtain local magnetic anomalies. This base station is re-occupied daily throughout the survey. Rover Magnetometer is the one that moved along the traverse line and recorded TMI values at each of the stations. This data is varied with location based on local magnetic intensity and is compared against base data and the anomaly is calculated.

Total Magnetic Intensity maps have been prepared after undertaking processes of base/regional corrections of the rover data which is shown in Figure 4. This resembles the high and low magnetic intensities of the study area based on the parameters like Latitude, Longitude, Inclination and Declination of the earth. Hence, the magnetic intensities are not truly higher as well as lower in Magnetic Intensity of the particular locations.

The observed total magnetic intensities are corrected for International Geomagnetic Reference field and the total magnetic intensity maps so generated (which is presented in Figure 5) for all the four areas are called as IGRF correctedTMI (Total magnetic Intensity) maps.

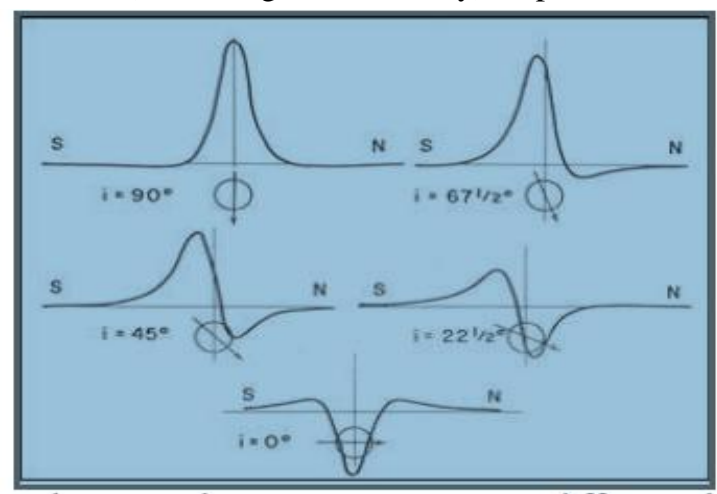

Fig.4. Showing the TMI variations at different latitudes

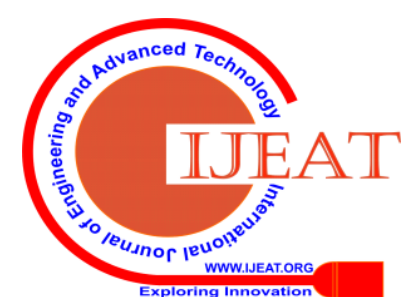




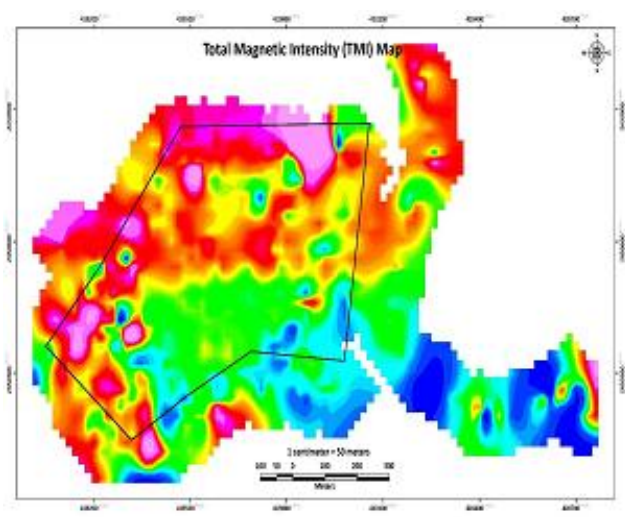

Fig.5. Diurnal and IGRF Corrected Total Magnetic Intensity (TMI) map of the Study Area

Reduce to Pole- The IGRF corrected data has been subjected to a kind of mathematical processing called Reduced to Pole (RTP) to make it more convincing. Reduction to the pole (RTP) transforms an observed TMI anomaly into an anomaly that would be measured at the north magnetic pole. As the study areas are falling over 20 degrees latitude. Therefore, it was essential to prepare Reduced to pole (RTP) maps using IGRF TMI data as of the magnetite responses for such low latitudes are similar to the anomalous near equator with prominent negative predominance which is show in Figure 6.

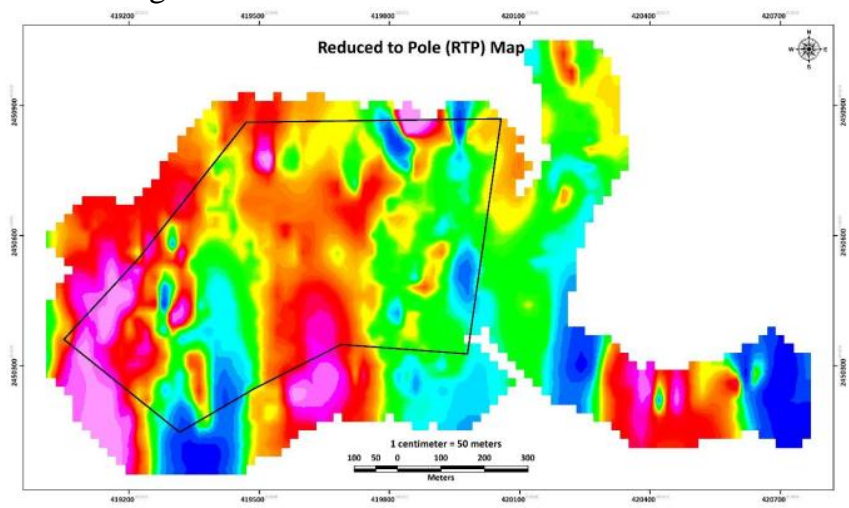

Fig. 6. Reduced to Pole (RTP) Map of the Study Area.

\section{RESULTS AND DISCUSSION}

The current study area consists of supracrustal rocks with dominant deposits of banded iron formation (BIF) and iron ores. The BIF mainly contains banded cherty quartzite (BCQ), banded magnetite quartzite (BMQ) and banded magnetite grunerite quartzite (BMGQ). Iron ores (both Haematite and Magnetite) usually ferro-magnetic in nature and easily respond to magnetic survey. BMQ and BMCQ are more sensitive to magnetometers than BCQ in this area.

The Gem Systems GSM-19 WALKMAG magnetometers are very sensitive to acquire minute magnetic intensities while walking through a traverse. After processing the obtained magnetic intensities, some standard corrections (like diurnal and IGRF) applied to produce Total Magnetic Intensity (TMI) maps for analysis. But Reduced to Pole (RTP) maps are more accurate than TMI to analyse the ore deposits, as it corrects the deviations of Earth's Magnetic Pole effect.

In this study, Oasis Montaj Geosoft software's Euler Depth Convolution method used to know the probable ore body depth extinction and Volume Pixel (Voxel) method used to know the probable ore body volume. For analysing Euler Depth Convolution and Voxel, many other maps like Analytical Signal (AS) map, Horizontal Derivative maps for both $\mathrm{X}$ and $\mathrm{Y}$ direction, Vertical Derivative map for $\mathrm{Z}$ direction, Upward and Downward Continuation maps were prepared which is shown in Figure 7.

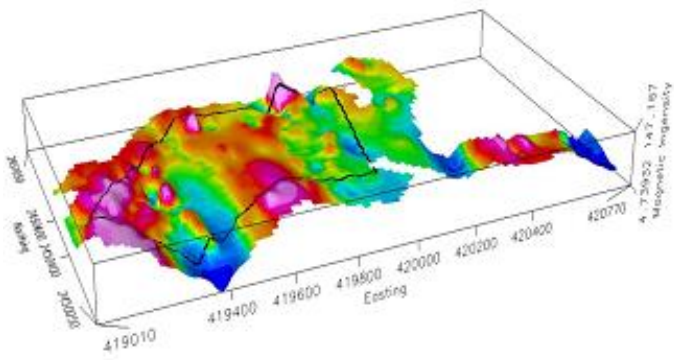

Fig. 7. 3D diagram of the Study Area

The resultant ore body total depths are obtained using Euler Depth Convolution method. It is not necessary that all the values represent the iron ore bodies. Wherever Structural Index 2 or horizontal body is matching in the magnetic susceptibility the values are produced by the software. Wherever depths shown in the non-priority areas (other than light pink and red colored zones), represent the flat or horizontal bodies of other minerals. The obtained probable depth of iron ore body from the software is plotted in Figure 8.

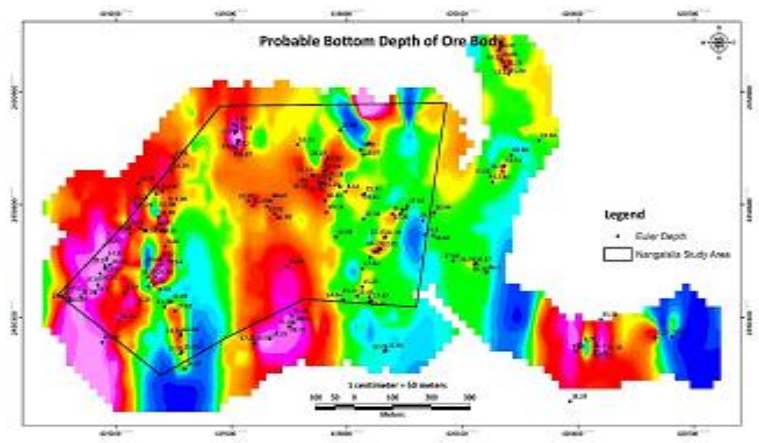

Fig. 8. Probable Bottom Depth of the Ore Body

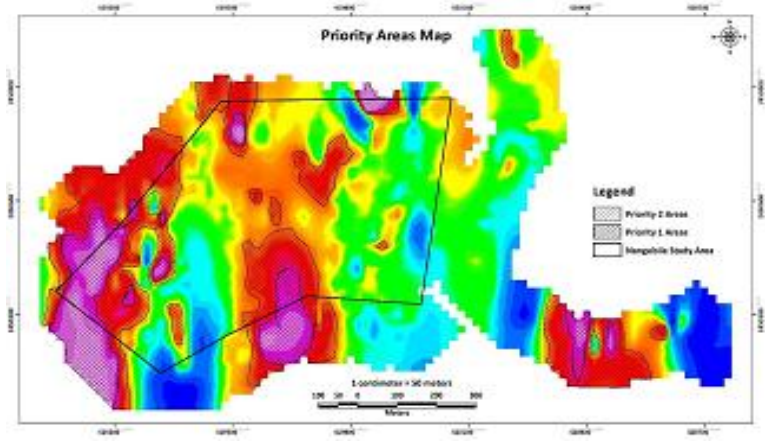

Fig. 9. Priority Areas based on Magnetic Studies

Priority Areas identified using analysis of magnetic anomalies, Euler Depth Convolution and Voxel methods. The priority area based on magnetic studies is plotted using software and presented in Figure 9.

Published By:

Blue Eyes Intelligence Engineering \& Sciences Publication 


\section{Identification of Probable Iron Ore using Ground Magnetic Exploration Technique}

The main principle of this analysis is that all the Iron Ore bodies are ferromagnetic in nature. Hence whenever high magnetic intensities or positive anomalies are shown in the analysed maps are considered as probable ore deposits. In other areas, ore deposits may be obtained, but in negligible quantities. But red colored zones may produce some quality amount of ore than other non-priority areas. All the light pink colored zones are delineated as probable high priority zones

\section{CONCLUSIONS}

The study of probable iron ore reserve was conducted using ground magnetic survey technique. After analyzing the magnetic data and with the primary field verification the following conclusions and recommendations are suggested to go for further exploration before any mining activities in considered site.

1. As per the current ground magnetic study, it is a confident suggestion that iron ore is available in this area. To arrive at the exact bottom depth of the ore body (in this study, only probable bottom depths are obtained), overburden thickness or to get exact thickness of the orebody, Vertical Electrical Sounding (VES) is recommended before pitting and trenching.

2. As per the field observations, the ore bodies available in this area are floats, deposited. To rule out this concept VES is recommended.

3. After getting the exact locations of the ore body and its thickness using VES, overburden etc details, it can be recommended that the pitting and trenching locations can be planned. If required drilling locations also can be planned.

4. Pitting and trenching was recommended mostly in the SW corner of the study area.

\section{REFERENCES}

1. B. Satpathy and D. Beura, Establishment of lithostratigraphy of some banded iron formations of iron ore super group of Odisha, India, International Journal of Engineering and Innovative Technology, 2013, 2(7), pp.146-50.

2. D. Beura, P. Singh and B. Satpathy, S. Behera and S.K. Nanda, Field relationship among the three iron ore groups of iron ore super group encircling the North Odisha Iron Ore Craton, India: a comparison study, Journal of Geosciences and Geomatics, 2016, 4(3), pp. 53-60.

3. D. Beura, Superposed deformation fabrics in the Precambrian rocks of the Iron Ore Super Group of Odisha, with special reference to Badampahar-Gorumahisani-Suleipat belt, 2015, 13, pp. 10-17.

4. T. Wise, M.J. Pawley, R.A. Dutch, Preliminary interpretations from the 2015 Coompana aeromagnetic survey, ASEG Extended Abstracts. 2016, 16(1), pp.1-6.

5. S.C. Mahala, Geology, Chemistry and Genesis of Thermal Springs of Odisha, India. Springer; 2019.

6. N. Belzile, Y.W. Chen and R. Xu, Early diagenetic behaviour of selenium in freshwater sediments, Applied Geochemistry, 2000,15(10), pp.1439-54.

7. P.C. Sahu, Studies on Geology And Mineral Resources of Mayurbhanj District, Odisha, India, 2018, 4 (1), pp 351 - 356.

8. G.S. Plumlee, The environmental geology of mineral deposits, The environmental geochemistry of mineral deposits. Society of Economic Geologists. Part A. 1999:71-116.

\section{AUTHORS PROFILE}

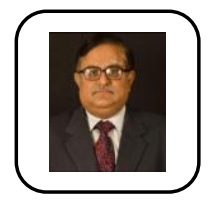

Dr K. S. Siva Subramanian Prof and head mining engineering department AMET University did doctorate in mineral exploration from IIT Mumbai. Has worked as Sr Vice President at MNC RMSI Pvt Ltd -Natural Resources business unit. He has 30 years of mining and mineral industry experience. He published 26 papers in international magazines and executed projects in 25 countries.

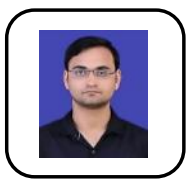

Dr. Abhishek Kumar Tripathi received his degree in Mining Engineering in the year 2014 from National Institute of Technology Rourkela, India. He earned his Ph.D. degree from National Institute of Technology Karnataka, Surathkal in the year of 2019. He has published 35 research articles in reputed journals and conferences. He is also a member of several professional bodies. He awarded as a Best Research Paper Award in 2nd International Conference on Paradigm in Engineering \& Technology (ICPET-2018) during 28th and 29th December 2018. He recognized and honored as a Fellow of Engineering Research Council (FERC) by Global Journals, a society Accredited ISO Certified and United State Corporation Under Open Association of Research Society (USA). Recently, he awarded as the excellent researcher award by International Academic and Research Excellence Award 2019 in association with GISR foundation Team. Currently, he is working as an Senior Assistant Professor in Aditya Engineering College (Autonomous), Surampalem, Andhra Pradesh, India. His research interests include Rock Mechanics, Renewable Energy Sources, Mines Power System, Mine Environment.

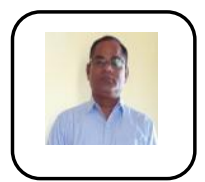

Mr. Ramesh Kant is working as a Faculty in Mining Engineering Department AMET University, Chennai. He has the 5 Years teaching experience. He also has the 8 years working experience in coal and metal mines Industry. He published 5 International Peer Reviewed Blasting Engineering.
Published By:
Blue Eyes Intelligence Engineering

\& Sciences Publication

(C) Copyright: All rights reserved. 